\title{
ATRIBUTOS LOCAIS DETERMINANTES NA CRIAÇÃO DE EMPRESAS
}

Silvio Paula Ribeiro ${ }^{1}$

Sirlei Tonello Tisott ${ }^{1}$

Tamires Sousa Araújo ${ }^{1}$

Alexandre Farias Albuquerque ${ }^{2}$

${ }^{1}$ Universidade Federal de Mato Grosso do Sul

${ }^{2}$ Universidade Federal de Mato Grosso do Sul - CPTL 


\section{ATRIBUTOS LOCAIS DETERMINANTES NA CRIAÇÃO DE EMPRESAS}

Resumo: Este artigo tem como objetivo analisar os atributos determinantes na criação de empresas no município do interior do país, pela perspectiva de potenciais empreendedores. Diante do exposto, aborda-se a questão: quais são os atributos determinantes à criação de empresas na perspectiva de potenciais empreendedores? O estudo caracteriza-se como survey, com abordagem quantitativa do problema. Os dados foram obtidos através da aplicação de questionário junto aos potenciais empreendedores. Para análise dos dados utilizou-se o software SPSS, versão 22, por meio da análise fatorial exploratória. Os resultados apontaram 10 (dez) atributos que influenciaram a criação de empresas: ações individuais, histórias de sucesso, compartilhamento de ideais, trabalhadores talentosos, universidades, serviços de apoio, capital de investimentos, política/governo, infraestrutura e abertura de mercado. Por fim, os atributos foram classificados em quatro categorias: cultural, suporte, capital e mercado local, com $67,95 \%$ de variância explicada.

Palavras-chave: Atributos do empreendedorismo. Criação de empresas. Potenciais empreendedores. Local empreendedor.

\section{Introdução}

A interação dos atributos disponíveis ao empreendedor potencializa o empreendedorismo na perspectiva local (SURESH; RAMRAJ, 2012). Lugares empreendedores incorporam instituições que interagem com os empresários de diferentes maneiras, atendendo ao estágio de vida da empresa e, o resultado destas interações é o fortalecimento da atividade local (FUENTELSAZ; MAICAS; MATA, 2017).

Nesta linha, diversos estudos abordam os atributos locais como fatores determinantes para à criação de empresas, tais como: Aoyama (2009), Diaconu e Duţu, (2015), Fritsch e Wyrwich (2017), Guerrero, Cunningham e Urbano (2015), Inácio Júnior et al. (2016), Isenberg (2011), Kibler, Kautonen e Fink (2014); Maícas et al. (2015), Miller e Acs (2017), Spigel (2016), Sousa et al. (2015), Stam (2015), Spigel e Harrison (2017), Urbano et al. (2017) e Vaillant e Lafuente (2007).

Os atributos podem ser classificados em culturais, sociais e materiais (SPIGEL, 2017). Contudo, Maícas et al., (2015) enfatizam que o empreendedorismo de oportunidade é influenciado positivamente por instituições de maior qualidade, sendo que, esta condição contribui com o desenvolvimento econômico. No entanto, Aparicio, Urbano e Audretsch (2016) consideram que o empreendedorismo não se beneficia das instituições automaticamente. Para que o benefício ocorra, são necessários mecanismos para servir como canal para a sociedade.

Diante desse contexto, estudos que abordam os atributos e as interpelações entre eles, tornam-se relevantes pela possibilidade de contribuir com a criação de empresas e, consequentemente com os aspectos econômicos e sociais de determinada localidade. Assim, este artigo tem como objetivo principal analisar os atributos determinantes na criação de empresas no município do interior do país, pela perspectiva de potenciais empreendedores. 
Para tanto, formulou-se a pergunta: quais são os atributos determinantes à criação de empresas na perspectiva de potenciais empreendedores?

Desta forma, foi solicitado aos potenciais empreendedores, alunos de cursos de graduação de universidades locais, que avaliassem a importância dos atributos locais ao empreendedorismo. Os resultados da análise fatorial permitiram reunir os atributos do empreendedorismo local em 4 (quatro) categorias: (cultural) atitudes individuais, histórias de sucesso e compartilhamento de ideais; (suporte): trabalhadores, universidades e serviços de apoio; (capital): capital de investimento e política do governo; e (mercado local): infraestrutura e abertura de mercado.

As considerações deste estudo atendem a uma das recomendações de Spigel (2017): estabelecer métricas para identificar a presença de atributos locais ao empreendedorismo. Ademais, essas pesquisas podem proporcionar possibilidade de compreensão de lugares empreendedores e, também, apontar como os atributos locais contribuem com a criação de empresas. Além, de contribuir com o direcionamento das políticas públicas ao empreendedorismo local.

\section{Referencial Teórico}

Em estudo sobre as políticas de apoio à criação de novas empresas na Espanha, Garrido e Pulido (2007, p. 33) afirmam que "nos últimos anos tem aumentando o número de instituições que apoiam o fomento à novas empresas". Quanto a importância do apoio do ambiente, Suresh e Ramraj (2012, p. 95) destacam que "cada vez mais evidências mostram que, os fatores ambientais também desempenham papel de contribuição ao processo de decisão em estabelecer novos empreendimentos".

Os atributos do empreendedorismo foram reunidos em 11 (onze) e classificados em culturais, sociais e materiais (SPIGEL, 2017). Na direção de aglutiná-los, Ribeiro (2019) classifica-os em categorias e subcategorias, além de ampliar o debate ao incluir: o valor cultural e os costumes locais, entre os atributos. Os atributos do empreendedorismo têm sido abordados para explicar a criação de empresas em determinado lugar. Para Spigel (2017, p. 50) os esforços devem "se concentrar nos atributos internos do local e como diferentes configurações desses atributos reproduzem e fornecem recursos para novos empreendimentos que eles não poderiam acessar".

Nesse sentido, Garrido e Pulido (2007, p. 43) evidenciam a necessidade de "contribuição e melhorias no conhecimento dos marcos institucionais na eficiência e a eficácia da gestão pública nas políticas de fomento e criação de novas empresas". No Brasil foram apontadas três dimensões de dependência externa aos empreendedores:

i) dependência do conhecimento; ii) dependência de colaboração e mercados favoráveis e iii) dependência de políticas públicas e cultura de apoio aos empreendedores. Considerando as três dimensões reveladas, pode-se concluir que as estratégias de estímulo e promoção do empreendedorismo no Brasil devem passar por políticas públicas que: i) incentivem a assimilação e a geração de crescimento; ii) estimulem a colaboração entre empreendedores; recursos financeiros e ampliar as redes de apoio aos empreendedores (SOUZA et al., 2015, p. 42). 
Em pesquisa realizada na província de Santa Fé na Argentina, Garcia et al. (2018, p. 232) afirmaram que "a cultura, o papel de facilitadores locais, as redes entre empresários, o quadro institucional de apoio e o grau de abertura do mercado local contribuem de forma relevante para a criação de empresas".

A proporção de pequenos e jovens empreendedores molda muitos aspectos do ambiente para criação de empresas: (i) crenças sobre a conveniência de fundar uma empresa, (ii) oportunidades de aprender sobre empreendedorismo e desenvolver as habilidades necessárias para ter sucesso e (iii) a facilidade de adquirir recursos críticos (SORENSON, 2017).

O Vale do Silício é citado como exemplo de lugares empreendedores, Saxenian (1995, p. 524) afirma que o vale "tem uma cultura de negócios orientada para a rápida introdução da inovação, não importa de onde ela veio, e uma história de colaboração no uso de inovações para novas oportunidades de negócios".

No entanto, estudo realizado em Hamamatsu e Quioto, no Japão (AOYAMA, 2009, p. 509) destacou que "a sobrevivência de lugares empreendedores depende da compreensão dos empresários de tecnologia da informação das práticas antigas das organizações e instituições regionais". Ainda, segundo o autor, o empreendedorismo local corresponde a evolução integral do complexo sistema local e evidencia a importância da cultural local para esta atividade. Nesta linha, Stephan e Pathak (2016, p. 505) defendem "maior foco no aspecto cultural, que conceitualmente são mais próximos do empreendedorismo".

As regiões alemãs com um alto nível de empreendedorismo em meados da década de 1920 têm taxas mais altas de startup, cerca de 50 anos depois. Assim, uma cultura regional do empreendedorismo é um atributo importante para a persistência da atividade no local. Além disso, descobriu-se que há um efeito significativo da atividade de startup no crescimento do emprego ao usar a cultura do empreendedorismo como instrumento para a atividade (FRITSCH; WYRWICH, 2017).

Os aspectos culturais relacionados à criação de empresas foram abordados como atributos do empreendedorismo local em diversas pesquisas (AOYAMA, 2009; KIBLER; KAUTONEN; FINK, 2014; RIBEIRO, 2019; ROUNDY; BROCKMAN; BRADSHAW, 2017; SORENSON, 2017; SPIGEL, 2017; STEPHAN; PATHAK, 2016; VAILLANT; LAFUENTE, 2007). Consideram-se como atributos culturais: valores culturais, atitudes, histórias de empreendedores e costumes locais.

Šebestová (2015) abordou os atributos do empreendedorismo em pesquisa realizada na região da Morávia-Silésia, na República Tcheca e considerou a localidade, a qualidade da força de trabalho, cooperação com órgãos públicos locais e relações comerciais entre fornecedores como os recursos determinantes do empreendedorismo local.

Miller e Acs (2017) realizaram estudo de caso para compreender os atributos do empreendedorismo disponível no Campus da Universidade de Chicago e, assim, considerou: a liberdade, a diversidade, a inovação, as oportunidades, a disponibilidade de ativos e a promoção ao empreendedorismo, como os atributos determinantes da atividade local.

Pesquisa realizada na Alemanha Ocidental concluiu que as regiões fornecem atributos locais que proporcionam oportunidades de negócios, sendo que, a experiência dos empregados na atividade industrial foi considera como principal atributo ao empreendedorismo local (AUDRETSCH et al. 2012). Contudo, Urbano et al. (2017) 
investigaram os fatores determinantes dos estudantes da Catalunya, na Espanha tornarem-se empreendedores e, consideraram a educação empreendedora como principal atributo.

Em relação ao Brasil, Souza et al. (2015, p. 30) afirmam que "os elementos sociais são mais importantes que as questões pessoais e as políticas públicas têm um papel essencial no desenvolvimento e manutenção do ecossistema empreendedor no Brasil". Ainda, segundo os autores, a cultura dos países em desenvolvimento possivelmente explica a atribuição de sucesso a condições externas em detrimento de valores e esforços pessoais.

Utilizando-se dados de painel com 43 países (2004-2012), considerou-se que as instituições informais têm um impacto positivo maior no empreendedorismo de oportunidades do que as instituições formais (APARICIO; URBANO; AUDRETSCH, 2017). Estudos de Aparício, Urbano e Audretsch (2016), Ibarra García et al. (2018), Maícas et al. (2015) e Veciana (2005) apontam a importância de lugares apresentarem oportunidades para novas empresas.

Os aspectos sociais relacionados à criação de empresas abordados como atributos do empreendedorismo local foram temas de diversas pesquisas (BRAMWELL; WOLFE, 2008; INÁCIO JÚNIOR et al. 2016; MILLER; ACS, 2017; RIBEIRO, 2019; SOUZA et al. 2015; SPIGEL; HARRISON, 2017; SPIGEL, 2017). Nesse estudo consideram-se como atributos sociais: as próprias redes, capital de investimento, mentores/negociadores, trabalhadores talentosos e oportunidades.

Dada a vitalidade e a força de lugares empreendedores pode ser possível avaliar o seu grau de maturidade e identificar o estágio de auto-sustentabilidade local. Bangalore, na Índia, pode ser considerado vibrante porque compreende todos os ingredientes-chave (política de apoio, universidades, profissionais qualificados, grandes empresas, capital de investimento, redes e cultura de apoio) de lugares empreendedores (SUBRAHMANYA, 2017).

Nesta direção, a universidade deve assumir o papel de orientar a atividade empreendedora e, assim, contribuir com o desenvolvimento econômico (DIACONU; DUȚU, 2015; GUERRERO; CUNNINGHAM; URBANO, 2015). Contudo, Urbano et al. (2017) investigaram os fatores determinantes dos estudantes da Catalunya, na Espanha tornarem-se empreendedores e, consideraram a educação empreendedora como principal atributo.

A universidade é destacada como atributo do empreendedorismo ao compreende-la como geradora de conhecimento, cientistas qualificados, meio de transferência de conhecimento, gera e atrai talentos para a economia local, colabora com a indústria local, fornecendo informações e suporte técnico. Programas de Cooperação e Educação Empresarial e uma política inovadora de Propriedade Intelectual, ilustra como a universidade contribuiu para o crescimento e a inovação na economia local e regional. Estas considerações foram realizadas em estudo de caso na Universidade de Waterloo, em Waterloo, Ontário, no Canadá (BRAMWELL; WOLFE, 2008).

Em pesquisa no contexto brasileiro verifica-se algum nível de ineficácia em iniciativas que visam promover o empreendedorismo acadêmico nas universidades brasileiras. As principais implicações estão relacionadas à dificuldade de adaptar estratégias que se mostraram bem-sucedidas em universidades específicas do contexto dos países desenvolvidos (FISCHER; MORAES; SCHAEFFER, 2019). Vale ressaltar que as universidades correspondem a um importante atributo local na criação condições para novas empresas. 
No entanto, Schaeffer, Fischer e Queiroz (2019, p.50) afirmam que "a criação de condições locais não é tão direta quanto às vezes anunciada no discurso político". Conforme Isenberg (2011), apesar da dificuldade, é crucial a adequação ao local por parte do governo das dimensões, clima e estilo de atividade. Ao analisar a evolução, a estrutura e o funcionamento do apoio à novas empresas, em Bangalore, na Índia, Subrahmanya (2017, p. 4) afirma que "os empresários analisam três aspectos em lugares empreendedores: os mercados acessíveis, o capital humano/força de trabalho e a disponibilidade de financiamento". Assim, Spigel (2017) considera como recursos materiais: universidades, serviços de apoio, infraestrutura, mercado aberto e política/governo. Para o autor, lugares que disponibilizam estes atributos potencializam o empreendedorismo na perspectiva local.

No Reino Unido, mais especificamente em Edimburgo, Spigel (2016, p. 141) analisou o papel da espessura institucional nos programas de tecnologia do local e, considerou a necessidade de uma visão holística que analise como eles funcionam em conjunto para fornecer suporte para criação e crescimento de empresas.

Desta forma, o Quadro 1, apresenta as categorias e subcategorias dos atributos do empreendedorismo.

\begin{tabular}{|} 
Quadro 1 - Categorias e subcategorias dos atributos do empreendedorismo \\
\hline CATEGORIAS & SUBCATEGORIAS \\
\hline \multirow{4}{*}{ CULTURAIS } & Ações individuais \\
\cline { 2 - 2 } & Histórias de sucesso \\
\cline { 2 - 3 } & Compartilhamento de ideais \\
\cline { 2 - 2 } & Costumes locais \\
\cline { 2 - 2 } & Redes próprias \\
\cline { 2 - 2 } & Capital de investimento \\
\cline { 2 - 3 } & Mentores e negociadores \\
\cline { 2 - 2 } & Trabalhadores talentosos \\
\hline \multirow{4}{*}{ MATIAIS } & Oportunidades \\
\cline { 2 - 2 } & Política/governo \\
\cline { 2 - 2 } & Universidades \\
\cline { 2 - 2 } & Serviços de apoio \\
\cline { 2 - 2 } & Infraestrutura \\
\cline { 2 - 2 } & Abertura de mercado \\
\hline
\end{tabular}

Fonte: Elaborada com base em Spigel (2017) e Ribeiro (2019)

Reunidos os atributos do empreendedorismo, apresentam-se no próximo item, os procedimentos de validação e credibilidade do estudo.

\section{Procedimentos Metodológicos}

Esta pesquisa caracteriza-se como survey e abordagem quantitativa (CRESWELL, 2010), utilizando-se técnicas estatísticas para coleta e tratamentos dos dados. Em relação ao enfoque, apresenta-se como estudo descritivo, pelo fato de que, pretende-se analisar e classificar as relações de fenômeno, específico. Neste caso, este artigo tem como objetivo principal analisar os atributos determinantes à criação de empresas em município no interior do Brasil na perspectiva de potenciais empreendedores. 
Discentes foram abordados em estudos de Bramwell e Wolfe (2008), Casero (2003), Urbano et al. (2017) e Urbano e Guerrero (2013) compreendidos como potenciais empreendedores, especificamente, os alunos de cursos da área de gestão. Portanto, fundamenta-se que os discentes têm condições de avaliar os recursos locais do empreendedorismo. Assim, por meio de questionário solicitou-se aos respondentes que emitissem conceitos, sobre os atributos locais à criação de empresas.

Com o propósito de estruturar a pesquisa e atender ao objetivo de estudo, adotou-se os seguintes componentes:

Quadro 2 - Componentes da pesquisa

\begin{tabular}{|c|l|}
\hline ITENS & \multicolumn{1}{|c|}{ DESCRIÇÕES } \\
\hline Revisão teórica e empírica & $\begin{array}{l}\text { Perspectiva dos atributos: culturais, sociais e materiais. } \\
\text { Revisão pesquisas empíricas: prioriza pesquisas que abordam o tema atributos } \\
\text { do empreendedorismo (AOYAMA, 2009; IBARRA GARCÍA et al., 2018; } \\
\text { MILLER; ACS, 2017; RIBEIRO, 2019; SOUSA et al., 2015; SPIGEL, 2017; } \\
\text { SUBRAHMANYA, 2017; URBANO et al. 2017). }\end{array}$ \\
\hline População & $\begin{array}{l}\text { Discentes (622 alunos) devidamente matriculados nos cursos de Administração } \\
\text { e Ciências Contábeis nas universidades do local pesquisado. }\end{array}$ \\
\hline Amostra & Por acessibilidade, sendo 132 (cento e trinta e dois) respondentes. \\
\hline Instrumento de pesquisa & Questionário de pesquisa adaptado de Spigel (2017) e Ribeiro (2019). \\
\hline Validação inicial & $\begin{array}{l}\text { Primeiro por um grupo de 5 (cinco) docentes. Os especialistas analisaram o } \\
\text { questionário e propuseram ajustes. }\end{array}$ \\
\hline Validação final & $\begin{array}{l}\text { Depois da revisão do questionário por especialistas, o mesmo foi aplicado a 10 } \\
\text { (dez) estudantes de Administração e Ciências Contábeis que não fizeram parte } \\
\text { da amostra. }\end{array}$ \\
\hline Coleta dos dados & Ocorreu entre os dias 01 de junho de 2019 e 30 de setembro de 2019. \\
\hline Organização dos dados & $\begin{array}{l}\text { Os dados foram tabulados em planilhas Excel. As informações foram obtidas } \\
\text { pelo software SPSS, versão 22. }\end{array}$ \\
\hline Análise dos dados & Utilizou-se da análise fatorial exploratória. \\
\hline
\end{tabular}

Fonte: Adaptado de Creswell (2010).

Diante do exposto, a questão de pesquisa definida foi quais são os atributos determinantes à criação de empresas na perspectiva de potenciais empreendedores? Após a revisão da literatura foi possível identificar os recursos culturais, sociais e materiais do empreendedorismo evidenciados em outros estudos (AOYAMA, 2009; IBARRA GARCÍA et al., 2018; RIBEIRO, 2019; SOUSA et al., 2015; SPIGEL, 2017).

$\mathrm{Na}$ análise dos dados verificou-se que não existem outliers, utilizou-se da análise fatorial exploratória, por meio do método de extração dos componentes principais, com a técnica de rotação varimax e os valores ausentes foram substituídos pela média. Segundo Hair et al., (2009), o modelo de análise de componentes é mais adequado quando existe a possibilidade de redução de dados e a análise fatorial fornece uma clara compreensão sobre quais variáveis podem atuar juntas e quantas variáveis podem ser consideradas como significativas no estudo.

Conforme mencionado, com o objetivo analisar os atributos determinantes à criação de empresas em município no interior do Brasil na perspectiva de potenciais empreendedores foram destacados 14 (quatorze) atributos apontados como explicativos do contexto na perspectiva local. Assim, após a definição dos atributos aplicou-se os questionários, junto aos 
potenciais empreendedores do local, onde os mesmos deveriam analisar, a participação dos atributos na criação de empresas.

O Quadro 3, reuniu os atributos do empreendedorismo em categorias, subcategorias e a descrição de cada dos respectivos recursos na perspectiva local.

Quadro 3 - Construto de pesquisa.

\begin{tabular}{|c|c|c|}
\hline \multicolumn{3}{|c|}{ ATRIBUTOS À CRIAÇÃO DE EMPRESAS } \\
\hline CATEGORIAS & SUBCATEGORIAS & DESCRIÇÕES \\
\hline \multirow{4}{*}{ CULTURAIS } & Ações individuais & $\begin{array}{l}\text { Têm ocorrido ações realizadas por indivíduos da localidade, com o } \\
\text { propósito de incentivar a abertura de novas empresas. }\end{array}$ \\
\hline & Histórias de sucesso & $\begin{array}{l}\text { As histórias de empresários que conseguiram êxitos no local são } \\
\text { utilizadas como fator motivador para novas empresas. }\end{array}$ \\
\hline & $\begin{array}{l}\text { Compartilhamento } \\
\text { de ideais }\end{array}$ & $\begin{array}{l}\text { O compartilhamento de ideais promovidos pelos líderes da sociedade } \\
\text { local tem ajudado no empreendedorismo local. }\end{array}$ \\
\hline & Costumes locais & Costumes locais tem sido utilizado para atrair novas empresas. \\
\hline \multirow{5}{*}{ SOCIAIS } & Redes próprias & $\begin{array}{l}\text { As próprias redes são formadas por profissionais que tentam captar } \\
\text { recursos para o empreendedorismo local. }\end{array}$ \\
\hline & $\begin{array}{c}\text { Capital de } \\
\text { investimento }\end{array}$ & $\begin{array}{l}\text { Existe disponibilidade de recursos financeiros e, estes tem atraído } \\
\text { novas empresas. }\end{array}$ \\
\hline & $\begin{array}{c}\text { Mentores e } \\
\text { negociadores }\end{array}$ & $\begin{array}{l}\text { Os mentores e negociadores correspondem às pessoas do local } \\
\text { (capital social/contatos) que atraem novas empresas. }\end{array}$ \\
\hline & $\begin{array}{l}\text { Trabalhadores } \\
\text { talentosos }\end{array}$ & $\begin{array}{l}\text { Existe disponibilidade de profissionais qualificados na cidade para } \\
\text { colaborar com novas empresas. }\end{array}$ \\
\hline & Oportunidades & A cidade oferece muitas oportunidades para novas empresas. \\
\hline \multirow{5}{*}{ MATERIAIS } & Política/governo & $\begin{array}{l}\text { Existem no local incentivos do governo (local, estadual ou federal) a } \\
\text { criação de empresas. }\end{array}$ \\
\hline & Universidades & $\begin{array}{l}\text { As universidades instaladas na cidade têm colaborado com a criação } \\
\text { de empresas. }\end{array}$ \\
\hline & Serviços de apoio & $\begin{array}{l}\text { Os serviços de apoio representam atividades oferecidas por } \\
\text { profissionais (contadores, administradores, economistas, } \\
\text { engenheiros, entre outros) para contribuir com o empreendedorismo } \\
\text { local. }\end{array}$ \\
\hline & Infraestrutura & $\begin{array}{l}\text { A infraestrutura física são as condições físicas (imóveis, ruas, } \\
\text { rodovias, aeroportos, hidrovias, gasoduto entre outras) } \\
\text { favorecem a atividade empreendedora. }\end{array}$ \\
\hline & Abertura de mercado & $\begin{array}{l}\text { A abertura de mercado se refere as condições de mercado que } \\
\text { facilitam a entrada de novos investidores. }\end{array}$ \\
\hline
\end{tabular}

Fonte: elaborado pelos autores (2019).

Desta forma, os respondentes analisaram por meio de escala 1 (um) a 5 (cinco), se o atributo tem contribuído com à criação de empresas na perspectiva local. Vale ressaltar que o instrumento de pesquisa foi devidamente validado, os dados coletados e organizados em planilha excel, em seguida, fez uso do software SPSS, versão 22, para realização da análise fatorial exploratória.

Considerações feitas em relação aos procedimentos metodológicos, na próxima sessão apresenta-se a análise dos dados.

\section{Análise dos dados}


O questionário de pesquisa utilizado para obter os dados foi dividido em três partes:

- Primeira: apresentação da pesquisa, obtenção do aceite dos participantes, informação aos participantes que os dados seriam analisados em conjunto, preservando a identidade dos respondentes.

- Segunda: algumas características dos respondentes, entre elas, sexo, idade, cidade onde reside e formação dos respondentes.

- Terceira: a última parte do instrumento de pesquisa buscou conhecer a percepção dos respondentes em relação aos quatorze atributos à criação de empresas na perspectiva local.

O perfil dos respondentes foi apresentado no Quadro 4:

Quadro 4 - Perfil dos respondentes

\begin{tabular}{|c|c|c|c|}
\hline CARACTERÍSTICAS & DETALHES & FREQUENCIAS & $\% \mathrm{~s}$ \\
\hline \multirow{3}{*}{ GÊNERO } & Masculino & 60 & 45,5 \\
\hline & Feminino & 67 & 50,8 \\
\hline & Não identificado & 5 & 3,7 \\
\hline \multirow{5}{*}{ IDADE } & até 20 anos & 45 & 34,1 \\
\hline & de 21 a 30 anos & 63 & 47,7 \\
\hline & de 31 a 40 anos & 17 & 12,9 \\
\hline & de 41 a 50 anos & 6 & 4,5 \\
\hline & de 51 a 60 anos & 1 & 0,8 \\
\hline \multirow{4}{*}{ FORMAÇÃO } & Ensino médio & 75 & 56,8 \\
\hline & Técnica & 27 & 20,4 \\
\hline & Graduação & 20 & 15,1 \\
\hline & Especialização & 10 & 7,7 \\
\hline \multirow{3}{*}{ RESIDÊNCIA } & Três Lagoas & 92 & 69,7 \\
\hline & Outro município de MS & 7 & 5,3 \\
\hline & Município de SP & 33 & 25 \\
\hline
\end{tabular}

Fonte: Elaborado pelos autores (2019).

A amostra da pesquisa é composta por 67 (sessenta e sete) mulheres representando $50,8 \%, 60$ (sessenta) homens representando 45,5\% e 5 (cinco) que não se identificaram corresponde a 3,7\% dos respondentes. Grande parte da amostra são jovens, com idade entre 20 (vinte) e 40 (quarenta) anos, com o seguinte grau de instrução: 56,8\% Ensino Médio; 20,4\% Ensino Técnico; 15,1\% Graduação e 7,7\% Especialização. A maioria $69,7 \%$ dos respondentes residem, atualmente, em Três Lagoas; $25 \%$ moram em cidades do interior de São Paulo e 5,3\% tem a residência em outras cidades do estado de Mato Grosso do Sul.

Desta forma, a análise com os 14 (quatorze) fatores apresentou os seguintes índices:

Tabela 1 - Resultado dos testes de consistência das 14 (quatorze) variáveis

\begin{tabular}{c|c|c|c}
\hline \multirow{2}{*}{ Alpha de Cronbach } & Esfericidade de Bartlett & \multirow{2}{*}{ KMO } & \multirow{2}{*}{ \% Variância explicada } \\
\cline { 2 - 2 } & Sig. & & 57,336 \\
\hline 0,814 & 0,00 & 0,790 & \\
\hline
\end{tabular}

Fonte: Elaborado pelos autores (2019). 
Os dados foram considerados confiáveis por meio do teste Alfa de Cronbach, onde o índice foi de 0,814. Em pesquisas de natureza exploratória, Hair et al. (2009) afirmam que este índice quando superior a 0,60 apresenta-se como aceitável. Para análise da adequação da amostra utilizou-se do teste KMO, que apresentou o resultado de 0,790. Para Marôco (2010) o KMO acima de 0,50 representa alta capacidade de fatorabilidade. Também, realizou-se o Teste de Esfericidade de Bartlett's, com o resultado de significância de 0,00, que para Hair et al. (2009) rejeita a probabilidade de que a matriz populacional seja idêntica.

A análise dos dados permite inferir que o conjunto de variáveis significativas explicam, conforme variância explicada $57,336 \%$ dos atributos do empreendedorismo local na perspectiva de potenciais empreendedores. Contudo, na análise das comunalidades foram excluídas as variáveis que apresentaram o índice inferior a 0,50. Atendendo, as sugestões de Hair et al. (2009, p. 123), "variáveis em geral deveriam ter comunalidades maiores que 0,50 para serem mantidas na análise".

As variáveis excluídas foram destacadas na tabela 2:

Tabela 2 - Variáveis excluídas da análise

\begin{tabular}{c|l|c}
\hline SUBCATEGORIAS & \multicolumn{1}{|c|}{ DESCRIÇÕES } & COMUNALIDADES \\
\hline Redes próprias & $\begin{array}{l}\text { As próprias redes são formadas por profissionais que } \\
\text { tentam captar recursos para o empreendedorismo local. }\end{array}$ & 0,457 \\
\hline Mentores e negociadores & $\begin{array}{l}\text { Os mentores e negociadores correspondem às pessoas do } \\
\text { local (capital social/contatos) que atraem novas empresas. }\end{array}$ & 0,424 \\
\hline Oportunidades & A cidade oferece muitas oportunidades a novas empresas. & 0,457 \\
\hline Costumes locais & Costumes locais tem sido utilizados para novas empresas. & 0,494 \\
\hline
\end{tabular}

Fonte: Elaborado pelos autores (2019).

Conforme mencionado, as variáveis mantidas na análise foram aquelas que, além de atenderam as recomendações de Hair et al. (2009), em relação ao índice de comunalidades acima de 0,50, também, enquadraram-se nas orientações dos valores de curtose e assimetria, que variam entre \pm 3 . A Tabela 3 apresenta as variáveis significativas:

Tabela 3 - Variáveis incluídas na análise

\begin{tabular}{c|c|c|c|c}
\hline CATEGORIAS & SUBCATEGORIAS & COMUNALIDADES & CURTOSES & ASSIMETRIAS \\
\hline \multirow{3}{*}{ CULTURAIS } & Ações individuais &, 576 &,- 389 &,- 393 \\
\cline { 2 - 5 } & Histórias de sucesso &, 664 &,- 457 &,- 317 \\
\cline { 2 - 5 } & Compartilhamento de ideais &, 726 &,- 670 &, 063 \\
\hline \multirow{3}{*}{ SOCIAIS } & Capital de investimento &, 657 &,- 650 &,- 204 \\
\cline { 2 - 5 } & Trabalhadores talentosos &, 664 &,- 817 &,- 124 \\
\hline \multirow{4}{*}{ MATERIAIS } & Política/governo &, 725 &,- 458 &,- 218 \\
\cline { 2 - 5 } & Universidades &, 632 &,- 409 &,- 543 \\
\cline { 2 - 5 } & Serviços de apoio &, 753 &,- 506 &,- 129 \\
\cline { 2 - 5 } & Infraestrutura &, 717 & $-1,021$ &,- 087 \\
\cline { 2 - 5 } & Abertura de mercado &, 682 &,- 389 &,- 393 \\
\hline
\end{tabular}

Fonte: Elaborado pelos autores (2019).

Mantidas no estudo, apenas as variáveis significativas, observa-se pequena redução no Alpha de Cronbach e no KMO, porém, os mesmos continuam atendendo as recomendações de 
Hair et al. (2009). E o aspecto positivo corresponde ao aumento do \% variância explicada, conforme tabela 4.

Tabela 4 - Resultado dos testes de consistência das 10 (dez) variáveis

\begin{tabular}{c|c|c|c|}
\hline \multirow{2}{*}{ Alpha de Cronbach } & Esfericidade de Bartlett & \multirow{2}{*}{ KMO } & \% Variância explicada \\
\cline { 2 - 2 } & Sig. & & 67,955 \\
\hline 0,750 & 0,000 & 0,714 & \\
\hline
\end{tabular}

Fonte: Elaborado pelos autores (2019).

Desta forma, as variáveis foram reunidas em 4 (quatro) componentes ou categorias, com autovalor superior a 1 e o \% variância explicada de 67,955. Conforme mencionado, os referidos índices atendem aos padrões estabelecidos por Hair et al. (2009).

Tabela 5 - Fatores explicativos do modelo utilizado

\begin{tabular}{ccccc} 
& \multicolumn{3}{c}{ VALORES PRÓPRIOS INICIAIS } & \\
\cline { 2 - 4 } COMPONENTES & TOTAL & VARIÂNCIA & CUMULATIVA & $\begin{array}{c}\text { SOMAS ROTATIVAS } \\
\text { \% CUMULATIVA }\end{array}$ \\
\hline 1 & 3,202 & 32,025 & 32,025 & 20,833 \\
2 & 1,363 & 13,628 & 45,652 & 39,997 \\
3 & 1,158 & 11,580 & 57,232 & 54,330 \\
4 & 1,072 & 10,723 & 67,955 & \\
5 &, 789 & & & \\
6 &, 673 & & \\
7 &, 622 & & \\
8 &, 440 & & \\
9 &, 354 & & \\
10 &, 327 & & \\
\hline
\end{tabular}

Fonte: Elaborado pelos autores (2019).

As recomendações de Hair et al. (2009, p. 115), sugerem que, o número de fatores deve ser "suficiente para atender um percentual especificado de variância explicada, geralmente de $60 \%$ ou mais”. Os detalhes das 4 (quatro) categorias estão na tabela 6:

Tabela 6 - Atributos do empreendedorismo reunidos em subcategorias e categorias

\begin{tabular}{|c|c|c|c|c|}
\hline \multicolumn{5}{|c|}{ ATRIBUTOS A CRIAÇÃO DE EMPPRESAS } \\
\hline \multirow[b]{2}{*}{ SUBCATEGORIAS } & \multicolumn{4}{|c|}{ CATEGORIAS } \\
\hline & 1 & 2 & 3 & 4 \\
\hline Capital de Investimento & & & 671 & \\
\hline Trabalhadores Talentosos & & ,759 & & \\
\hline Política de Governo & & & 824 & \\
\hline Universidades & & ,724 & & \\
\hline Serviços de Apoio & & ,795 & & \\
\hline Infraestrutura & & & & 798 \\
\hline Abertura de Mercado & & & & 768 \\
\hline Ações Individuais & ,742 & & & \\
\hline Histórias de Sucesso &, 750 & & & \\
\hline Compartilhamento de Ideais & ,748 & & & \\
\hline
\end{tabular}

Fonte: Elaborado pelos autores (2019). 
Os resultados permitem inferir que as 4 (quatro) categorias explicam 67,955\% dos atributos à criação de empresas na perspectiva de potenciais empreendedores. Assim, a resposta para: Quais são os atributos determinantes à criação de empresas na perspectiva de potenciais empreendedores? Encontra-se na Tabela 6. Além de apresentar, os atributos à criação de empresas, os mesmos, foram reunidos em 4 (quatro) categorias e denominadas, como: de ideais.

- Categoria 1 (cultural): atitudes individuais, histórias de sucesso e compartilhamento

- Categoria 2 (suporte): trabalhadores, universidades e serviços de apoio.

- Categoria 3 (capital): capital de investimento e política do governo.

- Categoria 4 (mercado local): infraestrutura e abertura de mercado.

Considerações realizadas em relação a análise dos dados, na próxima sessão procura-se discuti-los, conforme o contexto de outros estudos precedentes.

\section{Discussão dos resultados}

As configurações dos atributos do empreendedorismo foram abordadas e contextualizadas em vários lugares, conforme já foi mencionado e, as pesquisas mostram que os locais de empreendedorismo normalmente, se diferem, em relação ao oferecimento de recursos. Especialistas como: Spigel (2017) e Garcia et al. (2018) inferem que os locais de oportunidades de empreendedorismo podem se potencializar de diferentes maneiras.

Essa pesquisa reuniu os atributos do empreendedorismo local, em quatro categorias, com percentual de variância explicada de 67,95\% dos recursos determinantes do empreendedorismo na perspectiva local. Porém, a primeira categoria (atitudes individuais, histórias de sucesso e compartilhamento de ideais) é formada por atributos, que se identificam com os aspectos culturais e explicam 32,02\% do contexto local.

Desta forma, pode-se inferir que os atributos culturais do local são os de maior representatividade no fomento ao empreendedorismo, na perspectiva dos potenciais empreendedores. Esse resultado corrobora com Garcia et al. (2018, p. 232). Para os autores o papel de facilitadores locais corresponde a fator determinante ao empreendedorismo na província de Santa Fé na Argentina.

A importância da cultura local foi evidenciada em outros estudos realizados em: Hamamatsu e Quioto, no Japão (AOYAMA, 2009); Regiões alemãs com alto nível de empreendedorismo (FRITSCH; WYRWICH, 2017); Vale do Silício (SAXENIAN, 1995); Bangalore (SUBRAHMANYA, 2017); Canadá (SPIGEL, 2017).

Em relação as redes próprias que também, se enquadra como atributo cultural, os respondentes desta pesquisa, não consideram como determinante do empreendedorismo local. Vale ressaltar que estudos de Spigel (2017), Subrahmanya (2017), Saxenian (1995) e Garcia et al. (2018) apontaram a relevância deste recurso para a atividade. Assim, mesmo considerando que a quantidade de empresas que atuam no local pesquisado aumentou em números, o fato dos potenciais empreendedores não identificarem as redes próprias como relevante, proporciona preocupação com a atividade local. 
Vale ressaltar que Souza et al. (2015) ao investigarem o ecossistema brasileiro de empreendedorismo apresentou a necessidade de ampliação das redes de apoio ao empreendedorismo do país.

A segunda categoria foi definida como "suporte", e é formada pelos atributos: trabalhadores, universidades e serviços de apoio. Este grupo de recursos, segundo os potenciais empresários, é responsável por $13,62 \%$ do contexto da atividade empreendedora do local.

A força, qualidade ou talento dos trabalhadores locais foi destacado em outras pesquisas (AUDRETSCH et al. 2012; ŠEBESTOVÁ, 2015; SUBRAHMANYA, 2017) como atributo determinante do empreendedorismo local. Estas pesquisas foram realizadas, respectivamente, na República Tcheca, Alemanha Ocidental e Bangalore.

A participação das universidades como canal de disseminação do conhecimento empreendedor ou promoção do empreendedorismo foi apresentado em pesquisas de Bramwell e Wolfe (2008), de Guerrero, Cunningham e Urbano (2015), de Miller e Acs (2017), de Subrahmanya (2017) e de Urbano et al. (2017). Estes estudos ocorreram no Canadá, Chicago, Bangalore e na Espanha. Enquanto, que os serviços de apoio foram apontados como relevantes ao empreendedorismo (DIACONU; DUȚU, 2015; MILLER; ACS, 2017; ŠEBESTOVÁ, 2015; SUBRAHMANYA, 2017). Nesta direção, a criação de empresas em nível regional tende a se desenvolver cada vez mais baseada em acordos ou redes de cooperação entre as universidades, administração pública, câmaras de comércio, empresa privada, etc. em uma determinada região (VECIANA, 2005, p. 280).

A terceira categoria é o "capital", formado pelos atributos: capital de investimento e política do governo. Este item, segundo os potenciais empresários é responsável por 11,58\% do contexto da atividade empreendedora do local. Este resultado corrobora com outros resultados de Bramwell e Wolfe (2008), Spigel (2017) e Subrahmanya (2017).

Vale ressaltar que Souza et al. (2015) afirmam que o empreendedorismo brasileiro deve passar por políticas públicas que estimulem o capital financeiro para a atividade. E, quanto ao atributo político do governo que corresponde a existência no local de incentivos do governo (local, estadual ou federal) à criação de empresas, estudos de Isenberg (2011), Spigel (2016) e Subrahmanya (2017) apontam a relevância deste atributo ao empreendedorismo local.

No entanto, Maícas et al. (2015) ao abordarem os aspectos da política fiscal, surpreendem ao afirmarem que a liberdade fiscal afeta negativamente o empreendedorismo de oportunidade. A liberdade fiscal aumentaria a taxa de iniciativas de risco, que lançam pequenas empresas com o único propósito de garantir a subsistência de seus parceiros. Ribeiro (2019) apontou que as políticas de incentivos são oferecidas, essencialmente, as grandes empresas, o que, normalmente atrai outras inúmeras pequenas empresas. Contundo, as políticas de incentivos devem priorizar as pequenas empresas para, assim, fomentar o empreendedorismo local.

E, por fim, a quarta categoria foi nomeada como "mercado local" e é composta pelos atributos: infraestrutura e mercado aberto. Este item, segundo os potenciais empresários é responsável por $10,72 \%$ do contexto da atividade empreendedora do local. Vale ressaltar que outros estudos (BRAMWELL; WOLFE, 2008; ISENBERG, 2011; SPIGEL, 2017) apontaram a relevância deste ao empreendedorismo local. 
Portanto, as quatro categorias explicam $67,95 \%$ dos atributos do empreendedorismo local. Contudo, os estudos precedentes (IBARRA GARCÍA et al., 2018; MAÍCAS et al., 2015; VECIANA, 2005) indicam que os atributos do empreendedorismo local devem contribuir com oportunidades aos empreendedores. Porém, assim, como os mentores e negociadores que correspondem às pessoas do local (capital social/contatos) que atraem novas empresas, o item oportunidades também, não foi significante, conforme o resultado deste estudo. Portanto, aponta-se a necessidade de melhorias nos atributos do empreendedorismo local.

\section{Considerações finais}

Esse estudo teve como objetivo principal analisar os atributos determinantes do empreendedorismo em cidade de médio porte do Brasil na perspectiva de potenciais empreendedores. Para tal, realizou-se uma pesquisa survey, com abordagem quantitativa do problema. Os dados foram obtidos por meio da aplicação de questionário junto a 132 (cento e trinta e dois) estudantes. Para a análise dos dados fez-se uso do software SPSS, versão 22 e utilizou-se da análise fatorial.

Os resultados obtidos reuniram os atributos determinantes do empreendedorismo local, na perspectiva de potenciais empreendedores em quatro categorias:

- Categoria 1 (cultural): individuais, histórias de sucesso e compartilhamento de ideais.

- Categoria 2 (suporte): trabalhadores, universidades e serviços de apoio.

- Categoria 3 (capital): capital de investimento e política do governo.

- Categoria 4 (mercado local): infraestrutura e abertura de mercado.

Exposto as variáveis significativas, infere-se que na perspectiva de potenciais empreendedores as categorias representam percentual de variância explicada de $67,95 \%$ do contexto. Considera-se que os 10 (dez) atributos reunidos são os determinantes do empreendedorismo local.

Contudo, por não apresentarem significância, as variáveis: redes próprias, mentores/negociadores, oportunidade e costumes locais foram excluídas do modelo de análise. Ainda, pode-se considerar que os atributos em prol do empreendedorismo local carecem de melhorias.

Destacam-se como limitações dessa pesquisa a amostra. Porém, apresenta-se contribuições ao reunir o conjunto de atributos do empreendedorismo e classificá-los como determinantes do empreendedorismo local, conforme perspectiva de potenciais empreendedores. Outra contribuição refere-se à possibilidade de identificar os atributos que devem ser melhorados e, consequentemente contribuir com o empreendedorismo.

Recomenda-se como estudos futuros abordar o tema sob a perspectiva de pequenos empresários e analisá-lo, por exemplo, por meio de equações estruturais.

\section{Referências}

AOYAMA, Y.; Entrepreneurship and regional culture: the case of Hamamtsu and Kyoto, Japan. Regional Studies, [S. l.], v. 43, n. 3, p. 495-512, 2009. 
APARICIO, S.; URBANO, D.; AUDRETSCH, D. Institutional factors, opportunity entrepreneurship and economic growth: Panel data evidence. Technological Forecasting and Social Change, [S. l.], v. 102, p. 45-61, 2016.

AUDRETSCH, D. B.; FALCK, O.; FELDMAN, M. P.; HEBLICH, S. Local entrepreneurship in context. Regional Studies, [S. l.], v. 46, n. 3, p. 379-389, 2012.

BRAMWELL, A.; WOLFE, D. A.; Universities and regional economic development: The entrepreneurial University of Waterloo. Research Policy, [S. l.], 37, p. 1175-1187, 2008.

CRESWELL, J. W. O projeto de pesquisa: métodos qualitativo, quantitativo e misto. Porto Alegre: Artmed, 2010.

DIACONU, M.; DUȚU, A. The role of the modern university in supporting the entrepreneurial ecosystem. European Journal of Interdisciplinary Studies, $[S . l$.$] , v. 7, n. 1,$ p. 11-24, 2015.

FISCHER, B. B.; MORAES, G. S. ; SCHAEFFER, P. . Universities' institutional settings and academic entrepreneurship: Notes from a developing country. Technological Forecasting and Social Change, v. 147, p. 243-252, 2019.

FRITSCH, M.; WYRWICH, M. The effect of entrepreneurship on economic development an empirical analysis using regional entrepreneurship culture. Journal of Economic Geography, [S. l.], v. 17, p. 157-189, 2017.

FUENTELSAZ, L.; MAÍCAS, J. P.; MATA, P. Institutional dynamism in entrepreneurial ecosystems. In: Entrepreneurial ecosystems: place-based transformations and transitions. Berlim: Springer, v. 7. p. 45-65, 2017.

GARRIDO, N. T.; URBANO, D. P.; Políticas de apoyo a la creación de Empresas en España Un estudio de Casos. Boletín Económico de Gelo, [S. l.], v. 2905, p.33-46, 2007.

GUERRERO, M.; CUNNINGHAM, J. A.; URBANO, D. Economic impact of entrepreneurial universities`activities: an exploratory study of the United Kingdom. Research Policy, [S. l.], v. 44, p. 748-764, 2015.

HAIR, J. F.; ANDERSON, R. E.; TATHAM, R. L.; BLACK, W. C. Análise multivariada de dados. Porto Alegre: Bookman, 2009.

IBARRA GARCÍA, S.; FEDERICO, J.; ORTÍZ, M; KANTIS, H. ¿El ecosistema o los ecosistemas? Primeras evidencias de un ejercicio de tipologías sobre ciudades de la Provincia de Santa Fe (Argentina). Revista de Empreendedorismo e Gestão de Pequenas Empresas, São Paulo, v. 7, n. 3, p. 215-237, set. 2018. Disponível em: http://www.regepe.org.br/regepe/article/view/1243. Acesso em: 28 set. 2019.

INÁCIO JÚNIOR, E.; AUTIO, E.; MORINI, C.; GIMENEZ, F. A. P.; DIONISIO, E. A. Analysis of the brazilian entrepreneurial ecosystem. Desenvolvimento em Questão, Ijuí, v. 14, n. 37, p. 5-36, 2016.

ISENBERG, D. J. Introducing the entrepreneurship ecosystem: four defining characteristics. Forbes, [S. l.], 25 May 2011. Disponível em: http://www.forbes.com/sites/danisenberg 
/2011/05/25/introducing-the-entrepreneurship-ecosystem-four-defining-characteristics.

Acesso em: 02 ago. 2018.

KIBLER, E.; KAUTONEN, T.; FINK, M. Regional social legitimacy of entrepreneurship: implications for entrepreneurial intention and start-up behaviour. Regional Studies, [S. l.], v. 48, n. 6, p. 995-1015, 2014.

LAFUENTE, E.; YANCY, V.; RIALP, J. Regional differences in the influence of role models: comparing the entrepreneurial process of rural Catalonia. Regional Studies, [S. l.], v. 41, n. 6, p. 779-795, 2007.

MAÍCAS, J. P.; FUENTELSAZ, L.; GONZÁLEZ, C.; MONTERO, J. How different formal institutions affect opportunity and necessity entrepreneurship. BRQ Business Research Quarterly, [S.l.], v. 18, p. 246-258, 2015.

MILLER, D. J.; ACS, Z. J. The campus as entrepreneurial ecosystem: the University of Chicago. Small Business Economics, [S. l.], v. 49, n. 1, p. 75-95, 2017.

RIBEIRO, S. P. Hierarquização de atributos ao empreendedorismo em Três Lagoas MS. Tese apresentada no Programa de Pós-Graduação em Ciências Contábeis da Universidade do Vale do Rio dos Sinos - UNISINOS, Porto Alegre, 2019.

ROUNDY, P. T.; BRADSHAW, M.; BROCKMAN, B. K. The emergence of entrepreneurial ecosystems: a complex adaptive systems approach. Journal of Business Research, [S. l.], v. 86, p. 1-10, 2018.

ROUNDY, P. T.; BROCKMAN, B. K.; BRADSHAW, M. The resilience of entrepreneurial ecosystems. Journal of Business Venturing Insights, [S. l.], v. 8, n. 11, p. 99-104, 2017.

SAXENIAN, A. Regional advantage: culture and competition in Silicon Valley and Route 128. Harvard Journal of Law \& Technology, [S. l.], v. 8, n. 2, 1995.

SCHAEFFER, P.; Fischer, B. B.; QUEIROZ, S. . Beyond Education: The Role of Research Universities in Innovation Ecosystems. Foresight and STI Governance, v. 12, p. 50-61, 2018.

SORENSON, O. Regional ecologies of entrepreneurship. Journal of Economic Geography, [S. l.], v. 17, p. 959-974, 2017.

SOUZA, L. L. F.; GERHARD, F.; ROVERE, R. L.; CÂMARA, S. F. Empreendedorismo e criação de novos negócios: fatores-chave do ecossistema empreendedor brasileiro. Revista de Negócios, Blumenau, v. 20, n. 4, p. 30-43, out. 2015.

SPIGEL, B. Developing and governing entrepreneurial ecosystems: the structure of entrepreneurial support programs in Edinburgh, Scotland. International Journal of Innovation and Regional Development, [S. l.], v. 7, no. 2, p. 141-160, 2016.

SPIGEL, B. The Relational organization of entrepreneurial ecosystems. Entrepreneurship: Theory and Practice, $[S . \quad l],$.$\quad v. 41, n. 1, p. 49-72, 2017. Disponível em:$ https://ssrn.com/abstract=2892813. Acesso em: 23 jan. 2019. 
SPIGEL, B.; HARRISON, R. Toward a process theory of entrepreneurial ecosystems. Strategic Entrepreneurship Journal, [S. l.], v. 12, p. 151-168, 2017.

STAM, E. Entrepreneurial ecosystems and regional policy: a sympathetic critique. Research Institute Discussion Paper, Utrecht, series 15:07, 2015.

STEPHAN, U.; PATHAK, S. Beyond cultural values? Cultural leadership ideals and entrepreneurship. Journal of Business Venturing, [S. l.], v. 31, p. 505-523, 2016.

SUBRAHMANYA, M. B.; How did Bangalore emerge as a global hub of tech startups in Índia? entrepreneurial ecosystem - evolution, structure and role. Journal of Developmental Entrepreneurship, [S. l.], Vol. 22, No. 1, 2017.

SURESH, J.; RAMRAJ, R. Entrepreneurial Ecosystem: Case Study on the Influence of Environmental Factors on Entrepreneurial Success. European Journal of Business and Management, [S. l.], Vol 4, No.16, 2012.

URBANO, D.; APARICIO, S.; GUERRERO, M.; NOGUERA, M.; TORRENT-SELLENS, J. Institutional determinants of student employer entrepreneurs at Catalan universities. Technological forecasting and social change, [S. l.], v. 123, p. 271-282, 2017.

URBANO, D.; GUERRERO, M. Entrepreneurial universities: socioeconomic impacts of academic entrepreneurship in a European region. Economic Development Quarterly, [S. l.], v. 27, n. 1, p. 40-55, 2013.

VAILLANT, Y.; LAFUENTE, E. Do different institutional frameworks condition the influence of local fear of failure and entrepreneurial examples over entrepreneurial activity? Entrepreneurship and Regional Development, [S. l.], v. 19, p. 313-337, 2007.

VECIANA, J. M. La creación de empresas: un enfoque gerencial. Barcelona: La Caixa, 2005. (Colección Estudios Económicos). 